\title{
Reseña de Educación en Pandemia. Guía de supervivencia para docentes y familias de Mariana Maggio (2021) Ciudad Autónoma de Buenos Aires, Editorial Paidós.
}

\author{
Leila Zimerman \\ https://orcid.org/0000-0002-9791-8349 \\ zimerman.leila@gmail.com \\ Facultad de Filosofía y Letras | UBA | Argentina
}

A través de la reconstrucción de las escenas educativas más emblemáticas del 2020, se va develando esta obra que señala tendencias, organiza ideas e identifica propuestas. Tras la vorágine atravesada, producto de la pandemia, se desarrolla el relato de lo sucedido, valorando sobre todo el trabajo realizado por toda la comunidad educativa para garantizar el derecho a la educación. Al mismo tiempo, se construyen nuevos marcos de referencia y se replantean interrogantes en vistas de los cambios que aún no conocemos pero que, sabemos, vendrán.

La obra interpela a docentes, educadores, pedagogos, al mismo tiempo que a las familias, desde una mirada empática y comprometida. Se presenta, entonces, como una llave para reflexionar a través de diferentes perspectivas sobre algunas de las problemáticas educativas que nos atravesaron durante el primer año de la pandemia. El libro se organiza en tres partes que abordan lo acontecido desde diferentes dimensiones y a partir de allí proyecta nuevos futuros inspirados en la posibilidad de imaginar lo que viene y de reinventar el mundo.

La obra interpela a docentes, educadores, pedagogos, al mismo tiempo que a las familias, desde una mirada empática y comprometida. Se presenta, entonces, como una llave para reflexionar a través de diferentes perspectivas sobre algunas de las problemáticas educativas que nos atravesaron durante el primer año de la pandemia. 
En el primer apartado, "El año que educamos en peligro”, se recogen escenas de situaciones educativas que tuvieron lugar durante el 2020. En el marco de una coyuntura extraordinaria y adversa, los diferentes actores del sistema educativo tuvieron que salir a resolver con lo que estaba disponible y poner a disposición rápidamente propuestas de todo tipo. En este camino, se abrieron viejas y nuevas preguntas, se desarrollaron intervenciones para la enseñanza en contextos complejos y en tiempos mínimos. Toda esta producción dio lugar a un cúmulo de avances valiosos y valientes, pero al mismo tiempo sueltos y aislados que son recuperados y destacados en este apartado. En este recorrido surgen propuestas Ilamativas como las que deciden priorizar algunos de los contenidos centrales para abordarlos con mayor profundidad y desde diferentes enfoques. Esto además permite trabajar lo relevante y lo actualizado a partir de producciones auténticas y originales. También se hace referencia a las condiciones institucionales que hasta el ASPO ${ }^{1}$ parecían inamovibles y que producto de las circunstancias se modificaron velozmente, tales como las aulas sin límites espaciales o la percepción de un tiempo diferente, diluido y superpuesto. Por último, queda evidenciada la deuda de desigualdad en materia de inclusión digital junto a la certeza de que este derecho está directamente relacionado con el derecho a la educación.

En la segunda parte titulada "¿Y ahora qué hacemos? Un marco para reinventarnos" se propone un espacio para ensayar un enfoque prospectivo, un marco de referencia provisorio para abonar lo que sigue. Se elabora un cuadro de situación con una mirada más analítica con el propósito de poner a dialogar dimensiones que permitan realizar articulaciones pedagógicas y didácticas diferentes. Se asume que las propuestas educativas tienen que ser concebidas para tener una expresión física y una expresión virtual a la vez y estar orientadas por un horizonte de transformación. Se parte de los problemas de la realidad para orientar la mirada hacia afuera y facilitar la posibilidad de crear en colaboración.

Muchas de estas reflexiones se inscriben en el marco de perspectivas con las que la autora venía trabajando y al mismo tiempo incluyen construcciones originales que emergieron a raíz del contexto inédito atravesado. Lo que no ha cambiado es la sincera preocupación por la humanidad, por la conformación de colectivos con identidad, por la apertura de diálogos expandidos y por la inserción de todas y todos para transformar la realidad.

\section{Lo que no ha cambiado es la sincera preocupación por la hu- manidad, por la conformación de colectivos con identidad, por la apertura de diálogos expandidos y por la inserción de todas y todos para transformar la realidad.}


"Guía de Supervivencia" es el título del tercer apartado de la obra en el que se sugieren una serie de orientaciones para intervenir sobre las prácticas de la enseñanza desde un abordaje innovador. En esta parte, la autora, se dedica a proyectar ideas, propuestas e intervenciones desafiantes hacia el futuro, apoyadas siempre en el camino atravesado. Bajo el principio "conversaremos hasta que hayamos tejido un acuerdo" se explicita que cuando cambian las condiciones también lo hacen los encuadres y frente a ello es imprescindible construir nuevos acuerdos que permitan avanzar creciendo.

Asimismo, se presentan sugerencias concretas para las prácticas de la enseñanza: explicitar los criterios que entran en juego; ofrecer alternativas como planes que reconozcan distintos ritmos; construir desde la cercanía; recuperar el movimiento de los cuerpos; comprometer a la comunidad; e intentar volver a apasionarnos. Incluirlas o sostenerlas podrían contribuir a esta transformación tan anhelada.

En este último apartado, también se despliegan propuestas disruptivas y alentadoras con una profunda convicción: la concepción de la docencia como trabajo colectivo con potencia para articular con los diferentes actores del ámbito educativo. La autora sostiene que para la construcción de una educación más inclusiva, comprometida y renovada hace falta compromiso y políticas que acompañen garantizando derechos tales como la conectividad.

\section{La autora sostiene que para la construcción de una educación más inclusiva, comprometida y renovada hace falta compro- miso y políticas que acompañen garantizando derechos tales como la conectividad.}

El libro termina con un epílogo que conmueve y alienta como solo ella sabe hacerlo. Un final que hace vibrar a cualquiera que haya transitado este tiempo con compromiso y dedicación destacando la potencia de estar conectados desde la tarea y desde la reinvención de las prácticas de la enseñanza. Termina develando, que esta producción es el resultado de un trabajo incesante de creación, recreación, pero sobre todo de escucha, diálogo con el colectivo docente que tuvo que enfrentar una de las rupturas más intensas del último tiempo.

El valor de esta obra reside en la relevancia y pertinencia de las lecturas, reconstrucciones y proposiciones que Mariana Maggio comparte generosamente con la comunidad educativa para pensar e intervenir sobre las prácticas de la enseñanza en el marco de este contexto tan incierto y desafiante. Siempre plantando una mirada de esperan$z a$, un voto de confianza que interpela e inspira para la creación de propuestas educativas potentes, comprometidas y democratizadoras. 
El valor de esta obra reside en la relevancia y pertinencia de las lecturas, reconstrucciones y proposiciones que Mariana Maggio comparte generosamente con la comunidad educativa para pensar e intervenir sobre las prácticas de la enseñanza en el marco de este contexto tan incierto y desafiante.

Un libro que será el registro de un momento que de seguro ha dejado más huellas de las ahora mismo estamos en condiciones de reconocer. Un libro necesario para llenarnos de orgullo de todo lo construido durante la tempestad y para reconocer nuevos signos de pregunta, allí donde solía haber puntos finales. Un libro que vuelve a enunciar una realidad irreverente: el derecho a la inclusión digital es urgente y la reinvención de las prácticas de la enseñanza es imprescindible. 